\title{
Using computer simulations to plan construction projects accurately
}

\author{
Alison Smith", Rana Ead¹, Simaan Abourizk \\ ${ }^{1}$ Department of Civil Engineering, University of Alberta
}

\begin{abstract}
The three main objectives in construction projects are completing the project on time, within budget, and with good quality. Each construction project is unique and unpredictable making it beneficial to model the project before executing it. There are many ways to model a construction project; however, computer models are ideal. It is very costly and time consuming to experiment with the actual system. Therefore, by using a computer simulation, accurate data can be collected from the project without the time and cost drawbacks. The specific construction project researched is based on a real project from Fort Mcmurray Alberta, Canada. The construction project involved the delivery and erection of three different types of steel in a construction site. Once the steel has been delivered, it needs to be stored and then carried by forklift to one of two cranes to be erected. A schedule was provided for which days each type of material was expected to be delivered and erected, however this schedule did not account for the $20 \%$ chance that any delivery could be delayed by one day or the $10 \%$ chance that deliveries could be delayed by two days. A model project was created on Simphony.NET with the assumptions that work could commence the entire day ( 24 hours), the site has unlimited storage, and a delay in one delivery does not delay all the deliveries after it. The schedule for the project was then modified to reflect the results of the simulation. The modified schedule showed that several deliveries of materials were delayed. However, due to the model's assumptions and the time for erection being relatively short, the planned schedule for the erection of the materials was not delayed. By using the data collected from the computer simulation it was possible to more accurately plan the schedule for this construction project.
\end{abstract}

Key words:

construction, construction project, computer simulation, simulation, construction simulation, Fort McMurray

Cite as: : Smith A., Coleman P., Ead R. Abourizk S. 2019. Using computer simulations to plan construction projects accurately. Alberta Academic Review, Vol 2 (2) 69-70, WISEST Special Issue (non peer-reviewed), DOI 10.29173/aar70. 


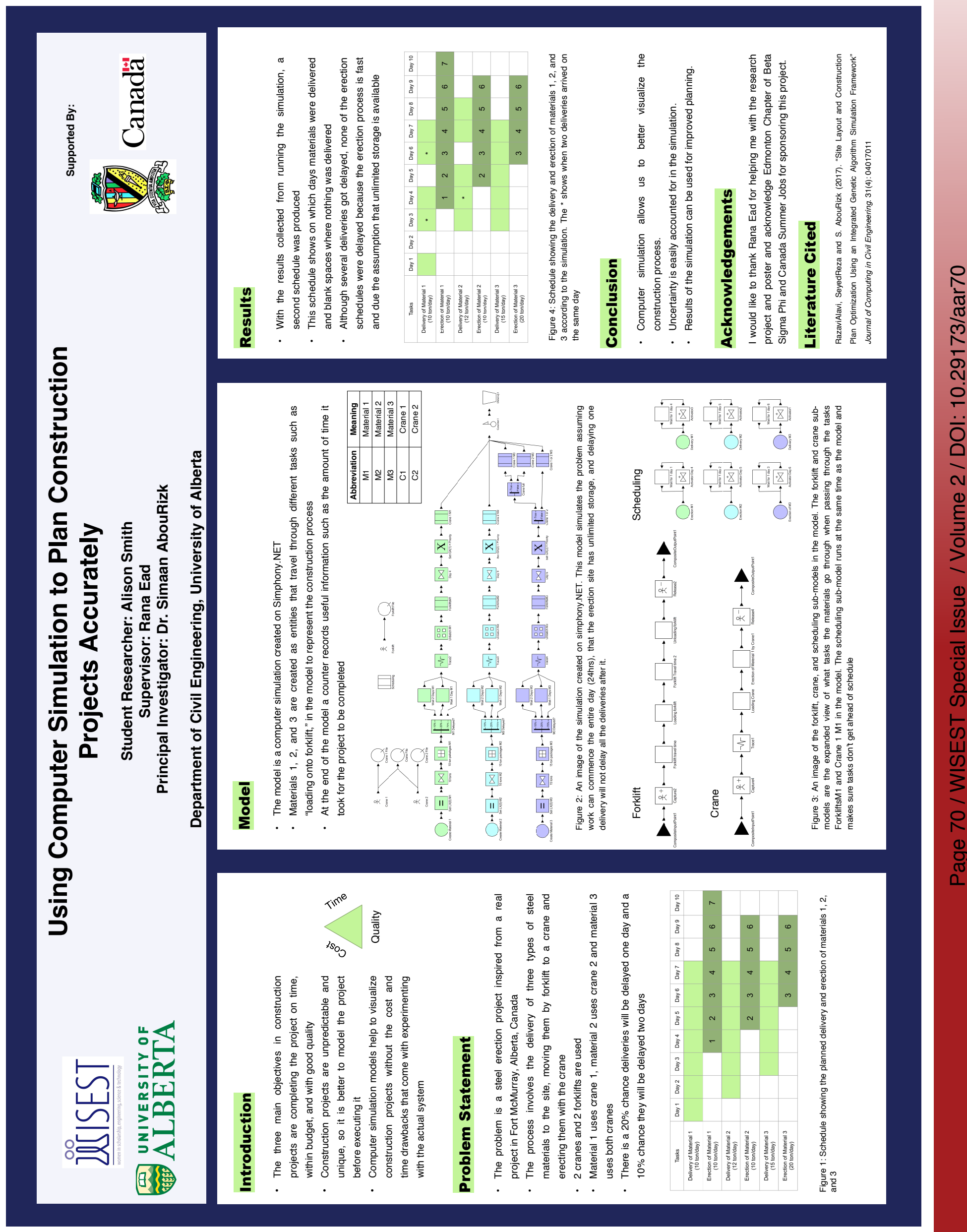

